\title{
HoNOS-ABI; a clinically useful outcome measure?
}

\author{
AIMS AND METHOD \\ Outcome measurement has become \\ increasingly important in brain injury \\ rehabilitation. Health of the Nation \\ Outcome Scale-Acquired Brain \\ Injury (HoNOS-ABI) is a new \\ outcome measure targeting psychia- \\ tric and other sequelae of brain \\ injury. Forty patients' scores on \\ three outcome measures and other \\ ecologically valid markers of \\ outcome were compared.
}

\author{
RESULTS \\ Significant correlation coefficients \\ between HoNOS-ABI and two other \\ outcome measures were found. Post- \\ injury employment status correlated \\ with HoNOS-ABI rating. Although \\ there was a significant increase in \\ need for psychiatric intervention \\ following brain injury, this did not \\ correlate with HoNOS-ABI ratings.
}

\author{
CLINICAL IMPLICATIONS \\ HoNOS-ABI may be a useful addi- \\ tional measure of outcome following \\ brain injury, specifically identifying \\ the often missed psychiatric sequelae \\ of a brain injury.
}

Brain injuries have devastating psychological, social and physical effects on individuals and their families. The acute medical care of individuals with a brain injury has made significant advances over the past couple of decades. This has resulted in an increased number of individuals surviving injury, who will need rehabilitation. The incidence of traumatic brain injuries is high, the annual figure for the UK being 300 per 100000 (Barnes et $a l, 1998)$. In a recent study in Scotland, Thornhill et al (2000) found that the incidence of disability following traumatic brain injury in adults was higher than expected. These results were thought to reflect the often unrecognised sequelae of a brain injury.

Although important methodological problems compromised studies that evaluated the effectiveness of rehabilitation, the overall conclusion following a review by Cope (1995) was that the efficacy of rehabilitation was strongly supported. Appropriate outcome measures were important to identify effective rehabilitation interventions and should tap dimensions of importance to the patient (Fleminger \& Powell, 1999).

It was important to recognise that psychiatric problems may follow an acquired brain injury (Deb et al, 1999). Measures that targeted the psychiatric consequences of brain injury were needed to identify treatment goals and to eventually evaluate outcome. The Health of the Nation Outcome Scale (HoNOS) (Wing et al, 1998) was primarily developed for use with adult psychiatric patients. During 1999 Fleminger and colleagues of the UK Brain Injury Psychiatrists Group adapted the scale for use with individuals who had sustained an acquired brain injury (HoNOS-ABl; available from the Royal College of Psychiatrists' College Research Unit, 6th floor, 83 Victoria Street, London SW1H OHW; tel 0207227 5320). It was thought that HoNOS was unlikely to become routine practice in the NHS, but that it may have an important role in service research (Stein, 1999).

\section{The study}

Forty patients' outcome ratings on the HoNOS-ABI, Portland Adaptability Inventory (Lezac, 1987) and the Grafton Manor Study Hierarchy of Placements (Eames, 1999) following brain injury were compared. The Portland Adaptability Inventory is a clinician rated scale designed to determine psychosocial outcome following brain injury. The three sub-scales included temperament and emotionality, activities and social behaviour and physical capabilities. The Grafton Manor Study Hierarchy of Placements (Hierarchical Rating of Residential Status) is used to compare change in residential status prior to and following rehabilitation. In this study of patients within the community, most of who did not receive any in-patient rehabilitation, only the current residential status was rated. All patients were rated retrospectively from intake and follow-up clinical notes (including information provided by carers) by the clinician that assessed and followed-up initially. The clinician was an experienced user of outcome scales for a brain-injured population. The HoNOS-ABI glossary, which contains the rating instructions, was used on each occasion to ensure consistency in the application of rating instructions. HoNOS-ABI has not been published and there are no published figures for the interrater reliability of the scales. The rater was unaware of the scores on the other measures of outcome when rating using HoNOS-ABI.

Other data collected included demographic variables, pre- and post-morbid psychiatric and employment status and indices of the severity of the brain injury sustained. Correlation coefficients were computed between the three rating scales (Spearman's rho) and other outcome data (point-biserial correlation coefficients for dichotomous variables). Psychiatric treatment was quantified by confirming from medical records that an individual was actually seeing a consultant psychiatrist (1) or not accessing such specialist intervention (0). 
Patients were all attending out-patient appointments with a community-based brain injury service. The average age of the patients was 35.25 years (s.d. $=13.39)$. Nine

original papers

$(22.5 \%)$ were female and $31(77.5 \%)$ male. The average period of loss of consciousness for the sample was 11.27 days (s.d. $=14.5)$. Thirty-four $(85 \%)$ sustained a severe brain injury, defined as a period of loss of consciousness of more than 1 day (Kraus \& McArthur, 1996). The type of injury was: trauma $(34,85 \%)$; stroke $(3,7.5 \%)$; infection $(1,2.5 \%)$ and anoxia $(2,5 \%)$. Time since the injury varied between 6 and 306 months ( $X=53.1$; s.d. $=66.84)$. Thirtythree were in full-time employment or education at the time of injury. Only four were receiving psychiatric treatment at the time of the injury.

\section{Findings}

Significant correlation coefficients were found between HoNOS-ABI summed scores (across the 12 scales) and the total score on the Portland Adaptability Inventory $(r=0.751, P<0.01)$ and the Grafton Manor Study Hierarchy of Placements $(r=0.446, P<0.01)$. Period of loss of consciousness did not correlate with HoNOS-ABI, but did reach significance for the Grafton Manor Study Hierarchy of Placements $(r=0.427, P<0.01)$. A negative correlation between loss of consciousness and post-injury psychiatric treatment was found $(r=-0.313, P<0.05)$.

The three most elevated sub-scales on the HoNOS$A B I$ were cognitive problems ( $m e a n=1.98$, median $=2$ ), problems with activities of daily living (mean $=1.63$, median $=2$ ) and problems with activities (mean $=1.45$, median=2). In contrast, the three lowest sub-scales were problems with hallucinations/delusions/confabulations ( mean $=0.33$, median $=0)$, self-directed injury ( mean $=0.33$, median $=0)$ and problem drink or drug use (mean $=0.55$, median $=0$ ).

Employment status post-injury correlated significantly with HoNOS-ABI $(r=0.616, P<0.01)$, the Portland Adaptability Inventory $(r=-0.558, P<0.01)$ and the Grafton Manor Study Hierarchy of Placements ( $r=-0.497$, $P=0.01$ ). No correlation between Glasgow Coma Scale (Teasdale \& Jennet, 1974) and HoNOS-ABI was found for a subgroup of patients $(n=13)$ for who Glasgow Coma Scale scores were available. Pre-morbid psychiatric status changed significantly following the brain injury, with more individuals needing psychiatric care $\left(\chi^{2}=4.18\right.$, d.f. $=1$, $P<0.05)$. Significantly more patients were unemployed following the brain injury when compared to pre-morbid employment status $\left(\chi^{2}=12.22\right.$, d.f. $\left.=1, P<0.01\right)$.

\section{Discussion}

This study found significant correlation coefficients between HoNOS-ABI and other measures of outcome in a post acute community-based service for individuals with an acquired brain injury. Higher HoNOS-ABI scores correlated with lowered employment status following brain injury. The finding that shorter periods of loss of consciousness correlated with increased need for psychiatric intervention was surprising. This may have reflected the increased emotional distress associated with better insight (Godfrey et al, 1993), perhaps following less severe brain injury. The absence of a correlation between HoNOS-ABI scores and uptake of psychiatric treatment possibly reflected a lack of formalised local referral systems and the general shortage of specialist services for this patient group, rather than a lack of actual need for specialist intervention.

There were several limitations to this study, including small sample size and the heterogeneity of the patient group. Although the results should be interpreted with care, the data from this study supported the use of HoNOS-ABI as an outcome measure for individuals with a brain injury in the community. The correlation of HoNOS$A B I$ with an ecologically valid outcome measure like employment status may be of particular significance. Psychiatric and psychological consequences of brain injuries, perhaps when combined with cognitive impairments, may pose significant obstacles to re-employment. It is likely that the financial implications, including loss of employment, following brain injury would take on more significance when evaluating outcome in future.

Multi-disciplinary interventions have been found to be more successful in brain injury rehabilitation (Semlyen et al, 1998). Using a range of outcome measures, including HoNOS-ABI, to identify the complex needs to be targeted during the rehabilitation process of this patient group is needed. Interrater reliability data and prospective studies of brain injury rehabilitation using HoNOS-ABI as an outcome measure is needed to determine its usefulness identifying change over time.

\section{References}

BARNES, M., EAMES, P., EVANS, C., et al brain injury. Neurological Clinics, 14, (1998) Rehabilitation AfterTraumatic Brain Injury. Working Party Report of the British Society of Rehabilitation Medicine. London: Royal College of Physicians.

COPE, D. N. (1995) The effectiveness of traumatic brain injury rehabilitation: a review. Brain Injury, 9, 649-670.

DEB, S., LYONS, I. \& KOUTZOUKIS, C. (1999) Neurobehavioural symptoms one year after a head injury. British Journal of Psychiatry, 174, 360-365.

EAMES, P. (1999) Measurement of outcome: development of an approach. Neuropsychological Rehabilitation, 9, 363-371.

FLEMINGER, S. \& POWELL, J. (1999) Evaluation of outcomes in brain injury rehabilitation. Neuropsychological Rehabilitation, 9, 225-230.

GODFREY, H. P., PARTRIDGE, F.M. KNIGHT, R. G., etal(1993) Course of insightdisorder andemotional dysfunctionfollowing closedheadinjury: a controlled cross-sectional followup study. Journal of Clinicaland Experimental Neuropsychology, 15,503-515.

KRAUS, J. F. \& MCARTHUR, D. L. (1996) Epidemiological aspects of 434-438.

LEZAC, M. D. (1987) Relationship between personality disorders, social disturbances, and physical disability following traumatic brain injury. Journal of HeadTraumaRehabilitation, 2, 57-69.

SEMLYEN, J. K., SUMMERS, S. J. \& BARNES, M. P. (1998) Traumatic brain injury: efficacy of multi-disciplinary rehabilitation. Archives of Physical Medical Rehabilitation, 79, 678-683.

STEIN, G. S. (1999) Usefulness of the Health of the Nation Outcome Scales. British Journal of Psychiatry, 174, 375-377.

TEASDALE, G. \& JENNET, B. (1974) Assessment of coma and impaired consciousness: a practical scale. Lancet, 13, 81-83.

THORNHILL, S., TEASDALE, G. M. MURRAY, G. D., et al (2000) Disability in young people and adults one year after head injury: prospective cohort study. BMJ, 320, 1631-1635.

WING, J. K., BEEVOR, A. S., CURTIS, R. H., et al (1998) Health of the Nation Outcome Scales (HoNOS). Research and development. British Journal of Psychiatry, 172, 11-18.

${ }^{*}$ Rudi Coetzer Consultant psychologist, North Wales Brain Injury Service, Colwyn Bay Hospital, Hesketh Road, Colwyn Bay, LL29 8AY, Pieter L. Du Toit Postgraduate PhD student, MRC Cognition \& Brain Sciences Unit, 15 Chaucer Road, Cambridge CB2 2EF 